\title{
A panel of markers for identification of malignant and non-malignant cells in culture from effusions
}

\author{
FABIANA PIRANI CARNEIRO ${ }^{1}$, MARIA IMACULADA MUNIZ-JUNQUEIRA ${ }^{2}$, \\ FABIO PITTELLA-SILVA ${ }^{2}$, MARCOS DE VASCONCELOS CARNEIRO ${ }^{3}$, \\ GUSTAVO HENRIQUE SOARES TAKANO ${ }^{1}$, LEONORA MACIEL DE SOUSA VIANNA ${ }^{1}$, \\ LUCIANO BARBOSA DE ANDRADE ${ }^{1}$, TERCIA MARIA MENDES LOUSA DE CASTRO ${ }^{2}$, \\ ISABELA PERES ${ }^{1}$, TATIANA KARLA DOS SANTOS BORGES ${ }^{2}$, \\ VÂNIA MORAES FERREIRA ${ }^{2}$ and ANDREA BARRETTO MOTOYAMA ${ }^{2}$ \\ ${ }^{1}$ Pathological Anatomy Center, University Hospital of Brasilia, ${ }^{2}$ Pathology Department of Brasília University, \\ ${ }^{3}$ Catholic University of Brasilia, Brasília, DF 71966-700, Brazil
}

Received April 12, 2017; Accepted July 24, 2017

DOI: $10.3892 /$ or.2017.6022

\begin{abstract}
The aim of the present study was to identify cell types in primary culture from malignant and non-malignant effusions. Effusion samples were subjected to cytology and culture. Immunocytochemistry was performed in cytological slides to evaluate malignancy (positivity for malignancy markers) and in culture slides for identification of cell types in growth. A total of 143 effusion samples (pleural $n=76$; peritoneal $n=37$; pericardial $n=4$; and peritoneal lavage $n=26$ ) were analyzed. Cell growth was observed in $34.9 \%$ of all samples and immunocytochemistry for identification of cell types in culture slides was conclusive in $90 \%$ of them. In non-malignant samples $(n=28)$, growth of mesothelial cells, macrophages and of both cell types was identified in 82.14 , 10.71 and $7.14 \%$, respectively. In malignant samples $(n=17$, all carcinomas), growth of malignant epithelial cells and of both malignant epithelial and mesothelial cells was identified in 41.17 and $23.52 \%$, respectively. In the remaining $35.29 \%$ of malignant samples, the only cells in growth were mesothelial and/or macrophages instead of malignant epithelial cells. In conclusion, in culture of malignant effusions, mesothelial cells may be simultaneously identified with malignant epithelial cells. Besides, mesothelial cells and macrophages may be the only cells identified in malignant effusion culture. Therefore, a broad panel of cell markers should be used for unmistakable identification of cells in studies of effusion primary culture. The ideal malignant effusion sample to obtain culture of
\end{abstract}

Correspondence to: Dr Fabiana Pirani Carneiro, Pathological Anatomy Center, University Hospital of Brasilia, UNB, Via L2 Norte, SGAN 604/605 Brasília, DF 71966-700, Brazil

E-mail: fabianapirani@hotmail.com

Key words: effusions, culture, immunocytochemistry, cytology, cancer, carcinoma neoplastic cells should be that without the presence of mesothelial cells and macrophages.

\section{Introduction}

Malignant effusion cell culture of patients with different cancers have been used to assess the response to chemotherapeutic agents, to provide in vitro characterization of neoplastic cell lines, to investigate tumoral heterogeneity and to understand the role of epithelial-mesenchymal transition (EMT) and cancer stem cells (CSCs) in metastasis and in high therapeutic failure rates (1-8).

Cytology of effusions (pleural, peritoneal and pericardial fluid) and peritoneal lavage is a routine procedure in pathological anatomy laboratories for the diagnosis, staging, determining the primary site of metastatic cancer and followup of patients with high incidence and mortality cancers such as carcinoma of breast, lung, ovary and stomach (9-11). The cell types usually identified by cytology of benign effusion are mesothelial cells, macrophages and leukocytes. Besides these cells, neoplastic cells may also be observed in malignant effusions (9-11). Effusions with high cellularity and characteristic morphological aspects enable to define the nature of the malignant cells (9-11). However, it should be noted that there are instances when the distinction between metastatic cancer cells and reactive or neoplastic mesothelium can be challenging (12-17). In these cases, immunocytochemistry may elucidate the origin of the atypical cells (12-17). Immunocytochemical panels typically include markers of mesothelial and of malignant epithelial cells but these markers do not exhibit high specificity and sensitivity and a broad panel of immunocytochemical markers is used for differentiating these cells (12-17).

Identification of cell types in culture of effusions is even more difficult than in cytology because the growing cells frequently undergo morphological and functional changes that in turn may also result in different expression pattern of immunocytochemical markers. In addition, there is the possibility of 
Table I. Antibody used in immunocytochemistry.

\begin{tabular}{llll}
\hline Antibody & \multicolumn{1}{c}{ Source } & \multicolumn{1}{c}{ Clone } & Dilution \\
\hline Anti-epithelial related antigen & Dako & MOC-31 & $1: 100$ \\
Anti-IMP3 & Dako & 69.1 & $1: 500$ \\
Anti-Claudin 4 & Abcam & AB15104 & $1: 200$ \\
Anti-Calretinin & Dako & DAK-Calret 1 & $1: 50$ \\
Anti-human mesothelial cell & Cell Marque & HBME-1 & $1: 50$ \\
Anti-Wilms' tumor 1 (WT-1) & Dako & $6 \mathrm{~F}-\mathrm{H} 2$ & $1: 300$ \\
Anti-CD68 & BioCare Medical & KP1 & $1: 100$ \\
Anti-vimentin & Dako & Clone V9 & $1: 100$ \\
Anti-pan-cytokeratin (PANCK) & Dako & AE1/AE3 & $1: 50$ \\
Anti-LCA & Dako & 4 KB5 & $1: 50$ \\
Anti-Melan-A & Dako & A103 & $1: 25$ \\
\hline
\end{tabular}

growth of various cell types (mesothelial, macrophages and epithelial malignant) simultaneously and failure to correctly identify them can interfere with subsequent research results. Therefore, in view of the potential use of culture of effusions and the need for the correct identification of cell types grown in culture, the aim of the present study was to identify by immunocytochemistry cells in culture from malignant and non-malignant effusions.

\section{Materials and methods}

Samples. Samples of effusions (pleural, peritoneal and pericardial) and peritoneal lavage were obtained at the Department of Pathology of Brasilia University Hospital, Brazil, between 2012 to 2015 . The study protocol was approved by the Human Ethics Review Committee of the Brasilia University.

Cytological and immunocytochemical analyses. All samples were centrifuged and the sediment was fixed in alcohol and stained by the Papanicolaou method. Cytology was considered positive for malignancy, negative, suspicious or unsatisfactory. Immunocytochemistry was performed in cytological slides to evaluate malignancy: the samples were divided into malignant (with positivity malignancy markers) and non-malignant (lack of positivity for malignancy markers).

Cell culture. The initial volume of the samples ranged from 10 to $50 \mathrm{ml}$. The unfixed samples were centrifuged, the supernatant was removed, and the cells were resuspended in $500 \mu \mathrm{l}$ of medium and then seeded onto a 4-well chamber slide, containing equal amount of complete Dulbecco's modified Eagle's medium (DMEM) supplemented with 20\% bovine fetal serum (FBS) and antibiotics and antifungals 2\% (penicillin, streptomycin and amphotericin B, $200 \mathrm{U} / \mathrm{ml}, 200 \mathrm{mg} / \mathrm{ml}$ and $2.5 \mu \mathrm{g} / \mathrm{ml}$ ). Samples were seeded in duplicate and culture slides were incubated at $37^{\circ} \mathrm{C}$ and $5 \% \mathrm{CO}_{2}$ for a total of 7 days, with medium change on the third day. On days 2 and 7, samples were washed and fixed in alcohol. Immunocytochemistry was also performed in culture slides for identification of cell types in growth.
Immunocytochemistry. For antigen retrieval, the slides were incubated for $45 \mathrm{~min}$ in a waterbath at $95-99^{\circ} \mathrm{C}$ with citrate buffer $\mathrm{pH}$ 6.0. For blockade of endogenous tissue peroxide, the slides were immersed in $3 \% \mathrm{H}_{2} \mathrm{O}_{2}$ solution at room temperature for $30 \mathrm{~min}$. After washing with phosphate buffered saline (PBS), the slides were incubated with primary antibody overnight at $4^{\circ} \mathrm{C}$. The primary antibodies used are shown in Table I. After washing with PBS, the slides were incubated with a secondary antibody for $30 \mathrm{~min}$ at room temperature and subsequently with the streptavidin-biotin-peroxidase complex (LSAB+; DAKO A/S, Glostrup, Denmark; K-690) for $30 \mathrm{~min}$ at room temperature. All reactions were developed using a diaminobenzidine chromogen solution (Dab substrate chromogen system-K3468; Dako). The counterstaining was performed with Harris hematoxylin. The slides were dehydrated, cleared and mounted. Positive and negative control were used for each primary antibody according to the manufacturer's recommendations. Positive staining was defined as a strong brown stain in more than $1 \%$ of cells in the cytoplasm (Pan-cytokeratin, CD68, vimentin and melan), membrane (HBME and LCA), nucleus (WT1), cytoplasm and membrane (MOC-31 and Claudin 4), cytoplasm and nucleus (calretinin and IMP3). The expression of at least two of the following markers was considered for identification of the mesothelial cell: calretinin, HBME and WT1. The expression of at least two of the following markers was considered for identification of the malignant epithelial cells: MOC, IMP3 and Claudin 4. The identification of macrophages was performed using the marker CD68 and lack of expression of epithelial markers. LCA and HMB-45 were used for identification of lymphoma and melanoma, respectively.

\section{Results}

Samples. A total of 143 samples (pleural effusion $n=76$; peritoneal effusion $n=37$; pericardial effusion $n=4$; and peritoneal lavagen $n=26)$ were analyzed. In $32.86 \%$ (47/143) of samples, patients presented with current or previous histological diagnostic of cancer (carcinoma $n=45$; lymphoma $n=1$; and melanoma $n=1$ ). 


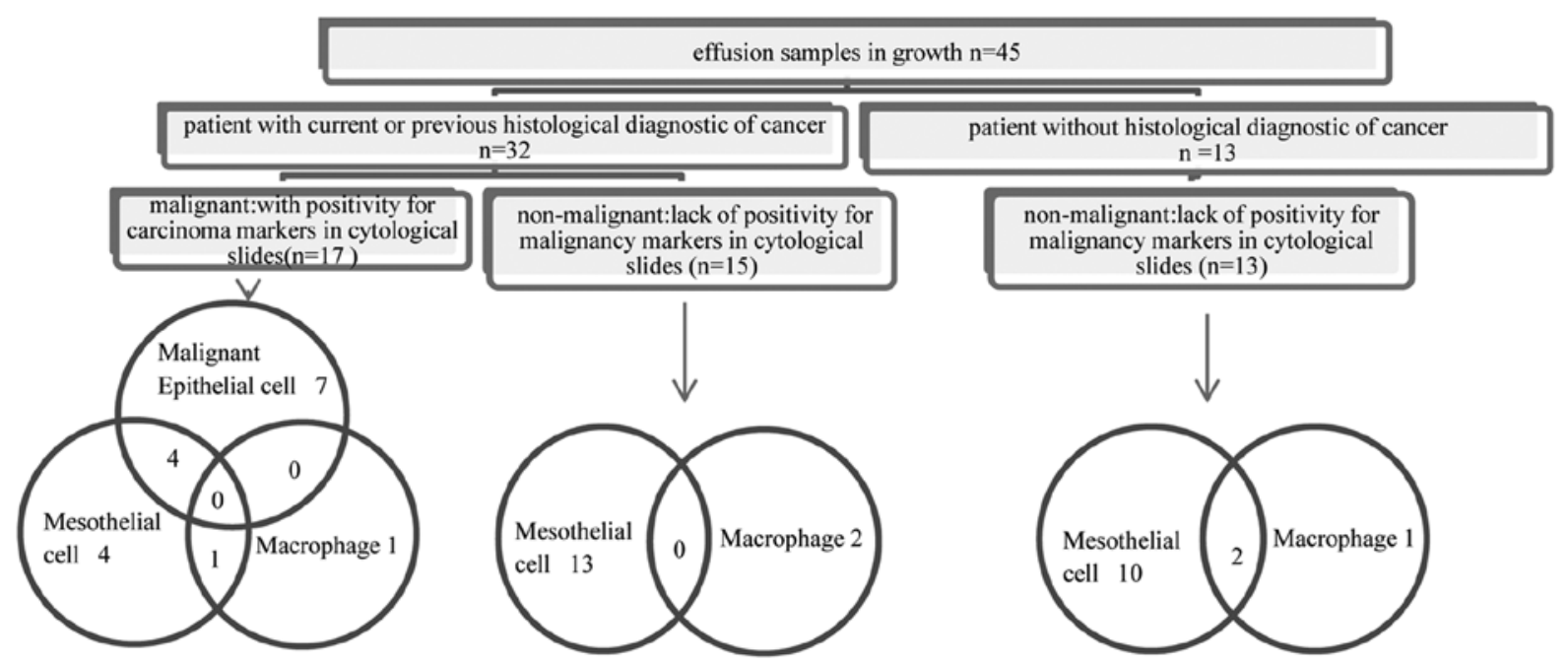

Figure 1. Cell types identified by immunocytochemistry in culture slides of malignant and non-malignant effusions.

Cytology, culture and immunocytochemistry. Cell growth was observed in $34.96 \%(50 / 143)$ of all samples (pleural effusion $n=31$ and peritoneal effusion $n=19$ ). After two days in culture, adherent cells formed a flat monolayer, and appeared homogenous and polygonal in shape on the seventh day. Because the cells were similar morphologically, immunocytochemistry was performed to identify the different cellular types in culture.

The identification of cell types in culture by immunocytochemistry was conclusive only in 90\% (45/50) of samples that showed growth. In the remaining 5 samples, low cellularity prevented the use of all necessary markers to complete immunocytochemistry analysis. In $71.11 \%$ (32/45) of samples in which immunocytochemistry was conclusive, patients presented with current or previous histological diagnostic of cancer but only in $37.77 \%$ (17/45), the samples were malignant (with positivity for carcinoma markers). In $62.22 \%$ (28/45), the samples were non-malignant (lack of positivity for malignancy markers) (Fig. 1).

The types of cells in culture identified by immunocytochemistry were mesothelial cell, malignant epithelial cell and macrophages.

In non-malignant samples, growth of mesothelial cells, macrophages and of both cell types were identified in $82.14 \%$ $(23 / 28), 10.71 \%(3 / 28)$ and $7.14 \%(2 / 28)$, respectively. In malignant samples, growth of malignant epithelial cells and of both malignant epithelial and mesothelial cells was identified in $41.17 \%$ (7/17) and $23.52 \%$ (4/17), respectively. In the remaining $35.29 \%(6 / 17)$ of malignant samples, the only cells in growth were mesothelial and/or macrophages instead of malignant epithelial cells (Fig. 1).

Presence of mesothelial cells in culture was identified by positivity for at least two of the markers calretinin, WT1 or HBME. The pattern of expression of the markers in adherent mesothelial cells in culture was similar to that of adjacent non-adherent mesothelial cells and to that of cells in cytology; cytoplasm and nucleus for calretinin, membrane for HBME and nucleus for WT1 (Figs. 2 and 3). Expression of nonspecific markers was also observed in the adherent mesothelial cells: pan-cytokeratin and vimentin. Malignant epithelial cells in culture were identified by positivity for at least two of the following markers: MOC-31, Claudin 4 and IMP3. The pattern of expression of the markers in adherent malignant epithelial cells in culture was similar to that of adjacent non-adherent malignant epithelial cells and to that of cells in cytology: cytoplasm and membrane for MOC-31 and Claudin 4, cytoplasm and nucleus for IMP3 (Fig. 3). Macrophages were identified by positivity for CD68 and lack of expression of epithelial markers. The staining pattern (cytoplasm) in adherent cells was similar to that of non-adherent adjacent cells and to that of cells in cytology.

\section{Discussion}

The aim of the present study was to identify, by a panel of immunocytochemical markers, cell types in primary culture from effusions. Although a large number of samples have been subjected to culture in this study, growth was obtained in only $34 \%$ of them. The low cellularity, mainly in peritoneal lavage, may explain, at least partially, the low number of samples with growth. To minimize the loss of cells, culture was performed directly on chamber slides and the interval between sample collection and culture of the samples was lesser than $48 \mathrm{~h}$, a period when the samples were kept at $4^{\circ} \mathrm{C}$ until culture. After culture and cytological analyses, the remainder of the sample was kept at $4^{\circ} \mathrm{C}$ for up to 2 weeks. Notably, in some of these samples, the presence of viable and capable of growth mesothelial cells was noted after such long-period storage (results not shown). Lack of adherence of the cells was another limiting factor to obtain a higher number of cultured samples. But cellularity and time of culture does not seem to be a determinant of adherence and growth of malignant epithelial cells in culture because in some samples in which many malignant epithelial cells (isolated or grouped) were present, no cell growth or only growth of mesothelial cells was identified, despite the high cellularity of malignant epithelial cells and even after 7 days of culture. This is in accordance with recent results which showed that cancer stem cells or tumor-initiating cells tend to grow in three dimensional cultures (18). 


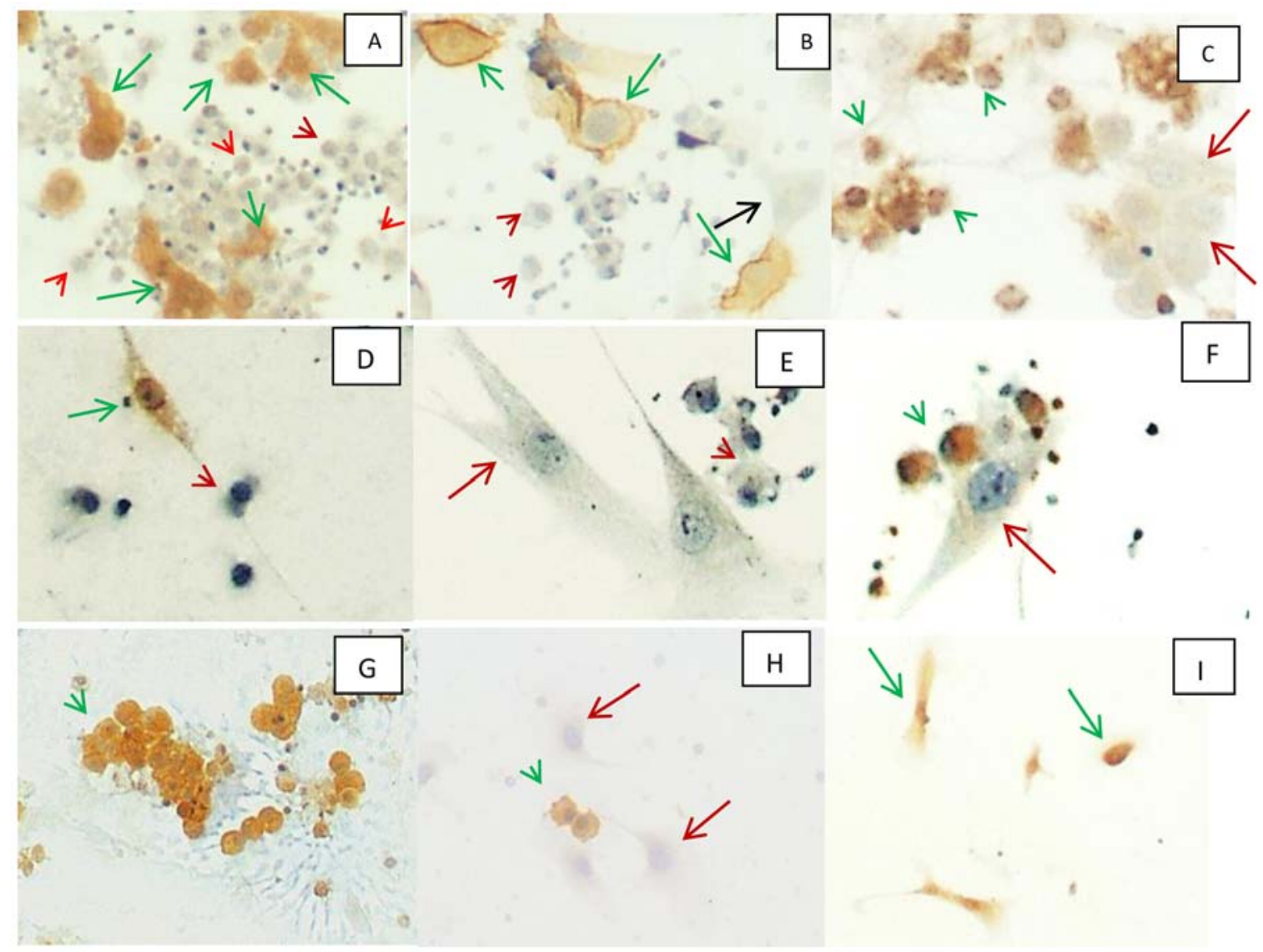

Figure 2. (A-C), culture of mesothelial cells from pleural effusion of patient with history of pneumonia. (A) Immunocytochemistry for calretinin (magnification, $\mathrm{x} 100$ ). Positive in cytoplasm and nucleus of adherent mesothelial cell (green arrow), negative in non-adherent macrophages (red arrowhead). (B) Immunocytochemistry for HBME (magnification, x100). Positive (green arrow) and negative (black arrow) in membrane of adherent mesothelial cells and negative in non-adherent macrophages (red arrowhead). (C) Immunocytochemistry for CD68 (magnification, x100). Positive in cytoplasm of nonadherent macrophages (green arrowhead), negative in adherent mesothelial cells (red arrow). (D-F) Culture of mesothelial cells from pleural effusion of patient with history of breast carcinoma and lack of positivity for carcinoma markers in cytological slides. (D) Immunocytochemistry for calretinin (magnification, x200). Positive in cytoplasm and nucleus of adherent mesothelial cells (green arrow), negative in non-adherent macrophages (red arrowhead). (E) Immunocytochemistry for MOC-31 (magnification, $\mathrm{x} 200$ ). Negative in adherent mesothelial cells (red arrow) and negative in non-adherent macrophages (red arrowhead). (F) Immunocytochemistry for CD68 (magnification, x200). Positive in cytoplasm of non-adherent macrophages (green arrowhead), negative in adherent mesothelial cells (red arrowhead). (G-I) culture of mesothelial cells from pleural effusion of patient with history of breast carcinoma and positivity for carcinoma markers in cytological slides. ( $\mathrm{G}$ and H) Immunocytochemistry for MOC-31 (magnification, x100). Positive in cytoplasm and membrane of non-adherent epithelial malignant cells (green arrowhead) and negative in adherent mesothelial cell (red arrow). (I) immunocytochemistry for calretinin (magnification, $\mathrm{x} 100$ ). Positive in cytoplasm and nucleus of adherent mesothelial cells (green arrow).

Morphologically, adherent mesothelial and malignant epithelial cells were indistinguishable in appearance and size, whereas macrophages were proportionally smaller as compared with those cells.

Using immunocytochemistry, it was possible to identify cell types in $90 \%(45 / 50)$ of the samples in culture. The expression pattern (nucleus, membrane and/or cytoplasm) of the markers remained at 2 and 7 days of growth, but one limitation of the present study was lack of analysis of markers expression for longer periods of time.

The predominant cell type of effusions in culture was mesothelial cells and they were present mainly in inflammatory benign or malignant effusions. Mesothelial cells are specialized epithelial cells that line the serous cavities (pleural, pericardial and peritoneal) (19). Under normal homeostasis, mesothelial cells exhibit limited cell proliferation, with only $0.16-0.5 \%$ of cells within the mesothelium undergoing mitosis at any one time $(19,20)$. The rate of mitosis increases to $30-60 \%$ following injury to the mesothelium, and this is attributed in part to increased levels of growth factors and cytokines (20-22). Culture and isolation of mesothelial cells has been used in studies on the role of mesothelial cells in the progression of cancer in malignant effusion (23-25).

A major contribution of this study was to demonstrate that in $65.62 \%$ of effusions of patient with current or previous histological diagnosis of cancer and in $35.29 \%$ of malignant effusion, the only cells found in culture were mesothelial and/or macrophages instead of malignant epithelial cells. Besides this, in $23.52 \%$ of malignant effusion, mesothelial and malignant epithelial cells were growing simultaneously in culture. When the objective is to obtain primary culture of malignant epithelial cells from a malignant effusion, the ideal sample should be without the presence of mesothelial cells and macrophages which are cells generally present when there is associated inflammation.

As the mesothelial cells were morphologically indistinguishable from malignant epithelial cells and no single marker is characterized by $100 \%$ specificity and sensitivity for 


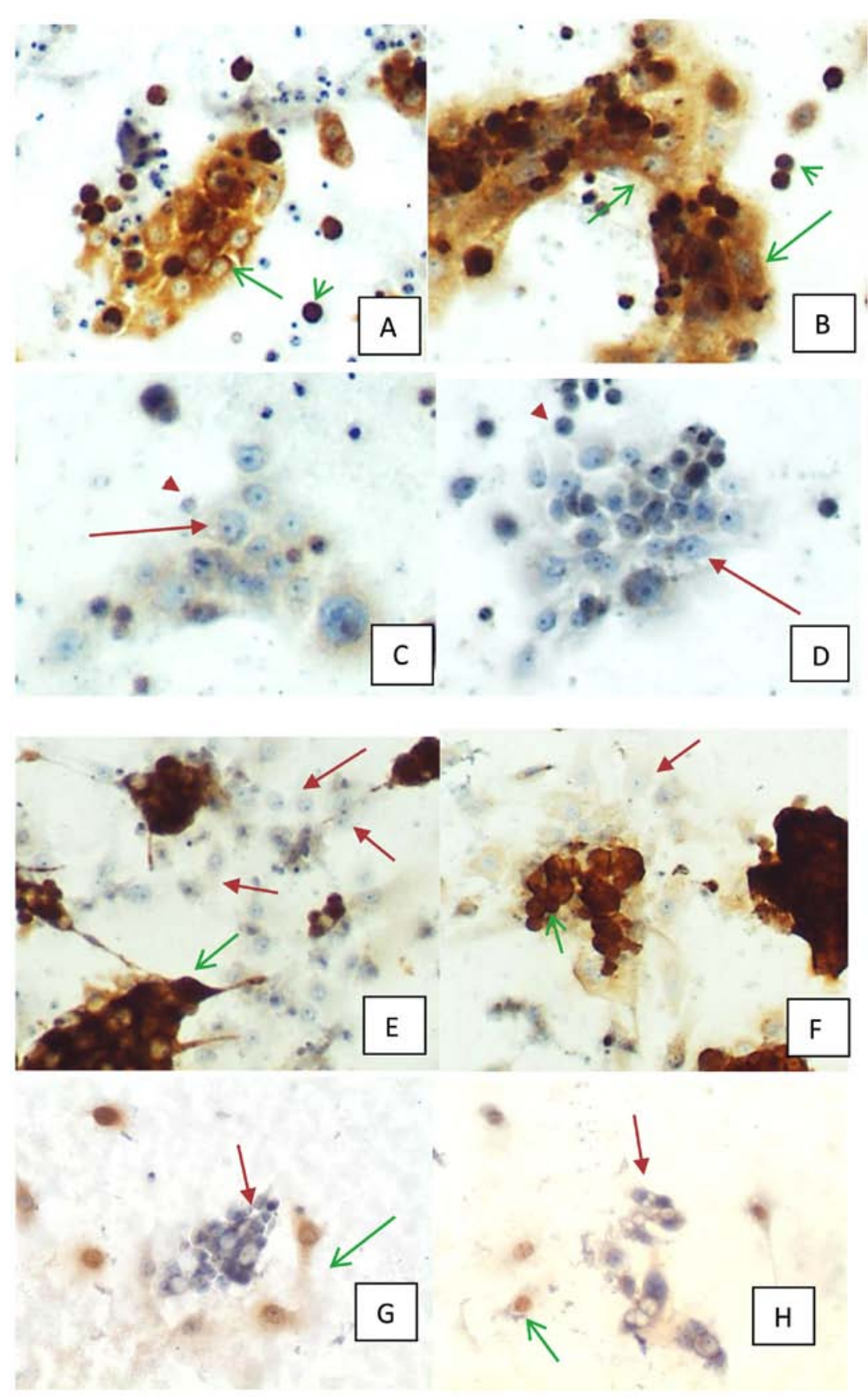

Figure 3. (A-D) culture of malignant epithelial cells from pleural effusion of a patient with history of esophagic cancer and positivity for carcinoma markers in cytological slides. (A) Immunocytochemistry for MOC-31 (magnification, x100). Positive in membrane and cytoplasm of adherent (green arrow) and nonadherent (green arrowhead) malignant epithelial cells. (B) Immunocytochemistry for IMP3 (magnification, x100). Positive in cytoplasm of adherent (green arrow) and non-adherent malignant epithelial cells (green arrowhead). (C) Immunocytochemistry for calretinin (magnification, x100). Negative in adherent (red arrow) and non-adherent (red arrowhead) malignant epithelial cells. (D) Immunocytochemistry for HBME (magnification, x100). Negative in adherent (red arrow) and non-adherent (red arrowhead) malignant epithelial cells. (E-H) Culture of both malignant epithelial and mesothelial cells from pleural effusion of patient with history of gastric carcinoma and positivity for carcinoma markers in cytological slides. (E) Immunocytochemistry for IMP3 (magnification, $\mathrm{x} 100$ ). Positive in cytoplasm of adherent malignant epithelial cells (green arrow), negative in adherent mesothelial cells (red arrow). (F) Immunocytochemistry for MOC-31 (magnification, x100). Positive in cytoplasm and membrane of adherent malignant epithelial cells (green arrow), negative in adherent mesothelial cells (red arrow). (G) Immunocytochemistry for calretinin (magnification, x100). Positive in cytoplasm and nucleus of adherent mesothelial cells (green arrow), negative in adherent malignant epithelial cells (red arrow). (H) Immunocytochemistry for WT1 (magnification, x100). Positive in nucleus of adherent mesothelial cells (green arrow), negative in adherent malignant epithelial cells (red arrow).

distinguishing these cells, a broad panel of markers should be used for the growth of mesothelial cells and macrophages not to be confused with growth of neoplastic cells in malignant effusions culture.

To the best of our knowledge, we have for the first time used a broad painel of immunocytochemical markers for identification of cells in primary culture from malignant and non-malignant effusions culture. The markers used here to identify mesothelial cells in growth were calretinin, HBME and WT1, but alternative markers could have be used such as thrombomodulin (14). Calretinin is a high sensitivity and specificity marker and widely used $(14,16,26,27)$. HBME was used, in the present study, for 
identification of mesothelial cells but it has a low sensitivity when compared to calretinin. Moreover, HBME can be expressed in certain types of carcinoma, such as lung, ovarian, breast, colon and stomach carcinoma $(14,28)$. WT1 expression can be detected in benign and malignant mesothelial cells. However, WT1 is a marker that is expressed in most of primary ovarian carcinomas and has been used to distinguish carcinoma of ovarian origin from carcinoma of other primary sites. Thus, although the expression of HBME and WT-1 could potentially cause some difficulty in the correct interpretation of effusion specimens, concomitant usage of other mesothelial cells and malignant epithelial cell markers could prove helpful $(15,29)$.

The markers used to identify malignant epithelial cells were MOC-31, Claudin 4 and IMP3, but several other adenocarcinomas markers have been used to distinguish malignant epithelial cells from mesothelial cells such as B72.3, CEA and Ber-EP4 (30-34). Besides, some primary site markers of adenocarcinoma can also contribute to distinction between mesothelial and epithelial malignant cells such as estrogen receptor, progesterone receptor, GATA3, mammoglobin, GCPD15 for breast; Napsin-A and TTF-1 for lung; CDX-2, villin, SATB2 for gastrointestinal tract; PSA for prostate; PAX8, HBME and estrogen receptor for ovary; CD10 and PAX 8 for kidney; hepatocyte-specific antigen for liver. As no single marker presents $100 \%$ specificity and sensitivity, positivity for a combination of markers have been used for identification of primary site markers of adenocarcinomas (35-45). For the diagnosis of squamous cell carcinoma, the negativity for MOC-31, negativity for mesothelial cell markers, and positivity for P63 may be useful (46).

In conclusion, the present study showed that in culture of malignant effusions, mesothelial cells may be simultaneously identified with malignant epithelial cell. Mesothelial cells and macrophages may be the only cells identified in malignant effusion culture. Therefore, a broad panel of cell markers should be used for identification of cells in studies of effusion primary culture. The ideal malignant effusion sample to obtain culture of neoplastic cells should be that without the presence of mesothelial cells and macrophages. These data will prevent future errors in studies using cells isolated from effusion cultures.

\section{Acknowledgements}

The present study was funded by the Fundação de Apoio a Pesquisa do Distrito Federal (FAP-DF), Fundação de Ensino e Pesquisa em Ciências da Saúde (FEPECS), FAHUB, CAPES and CNPQ.

\section{References}

1. Ruiz C, Kustermann S, Pietilae E, Vlajnic T, Baschiera B, Arabi L, Lorber T, Oeggerli M, Savic S, Obermann E, et al: Culture and drug profiling of patient derived malignant pleural effusions for personalized cancer medicine. PLoS One 11: e0160807, 2016.

2. Roscilli G, De Vitis C, Ferrara FF, Noto A, Cherubini E, Ricci A, Mariotta S, Giarnieri E, Giovagnoli MR, Torrisi MR, et al: Human lung adenocarcinoma cell cultures derived from malignant pleural effusions as model system to predict patients chemosensitivity. J Transl Med 14: 61, 2016.

3. Bezdieniezhnykh N, Lykhova A, Semesiuk N, Okhrimenko R and Kudryavets Y: Establishment and characterization of new breast and ovarian cancer cell lines as a model for studying cellular plasticity in vitro. Exp Oncol 38: 94-100, 2016.
4. Ku JL, Park SC, Kim KH, Jeon YK, Kim SH, Shin YK, Noh DY, Im SA, Bang YJ, Han W, et al: Establishment and characterization of seven human breast cancer cell lines including two triple-negative cell lines. Int J Oncol 43: 2073-2081, 2013.

5. Basak SK, Veena MS, Oh S, Huang G, Srivatsan E, Huang M, Sharma S and Batra RK: The malignant pleural effusion as a model to investigate intratumoral heterogeneity in lung cancer. PLoS One 4: e5884, 2009.

6. Ricci A, De Vitis C, Noto A, Fattore L, Mariotta S, Cherubini E, Roscilli G, Liguori G, Scognamiglio G, Rocco G, et al: TrkB is responsible for EMT transition in malignant pleural effusions derived cultures from adenocarcinoma of the lung. Cell Cycle 12: 1696-1703, 2013.

7. Chen SF, Lin YS, Jao SW, Chang YC, Liu CL, Lin YJ and Nieh S: Pulmonary adenocarcinoma in malignant pleural effusion enriches cancer stem cell properties during metastatic cascade. PLoS One 8: e54659, 2013.

8. Yin T, Wang G, He S, Shen G, Su C, Zhang Y, Wei X, Ye T, Li L, Yang S, et al: Malignant pleural effusion and ascites induce epithelial-mesenchymal transition and cancer stem-like cell properties via the vascular endothelial growth factor (VEGF)/ phosphatidylinositol 3-kinase (PI3K)/Akt/mechanistic target of eapamycin (mTOR) pathway. J Biol Chem 291: 26750-26761, 2016.

9. Francis IM, Alath P, George SS, Jaragh M, Al Jassar A and Kapila K: Metastatic breast carcinoma in pleural fluid: Correlation of receptor and HER2 status with the primary carcinoma - a pilot study. Diagn Cytopathol 44: 980-986, 2016.

10. Kalogeraki A, Lazopoulos G, Papadakis GZ, Tamiolakis D, Karvela-Kalogeraki I, Karvelas-Kalogerakis M, Segredakis J, Papadakis M, Moustou E, Datseri G, et al: Cytology of pericardial effusion due to malignancy. Rom J Intern Med 54: 179-183, 2016.

11. Kalogeraki A, Tamiolakis D, Datseri G, Lazopoulos G, KarvelasKalogerakis M, Segredakis J and Zoi I: Pleural effusion cytology due to malignancy. A combined cytomorphological-immunocytochemical study of 500 cases. Rev Port Pneumol 2006 22: 290-291, 2016.

12. Antonangelo L, Sales RK, Corá AP, Acencio MM, Teixeira LR and Vargas FS: Pleural fluid tumour markers in malignant pleural effusion with inconclusive cytologic results. Curr Oncol 22: e336-e341, 2015.

13. Westfall DE, Fan X and Marchevsky AM: Evidence-based guidelines to optimize the selection of antibody panels in cytopathology: Pleural effusions with malignant epithelioid cells. Diagn Cytopathol 38: 9-14, 2010.

14. Su XY, Li GD, Liu WP, Xie B and Jiang YH: Cytological differential diagnosis among adenocarcinoma, epithelial mesothelioma, and reactive mesothelial cells in serous effusions by immunocytochemistry. Diagn Cytopathol 39: 900-908, 2011.

15. Lyons-Boudreaux V, Mody DR, Zhai J and Coffey D: Cytologic malignancy versus benignancy: How useful are the 'newer' markers in body fluid cytology? Arch Pathol Lab Med 132: 23-28, 2008.

16. Saleh HA, El-Fakharany M, Makki H, Kadhim A and Masood S: Differentiating reactive mesothelial cells from metastatic adenocarcinoma in serous effusions: The utility of immunocytochemical panel in the differential diagnosis. Diagn Cytopathol 37: 324-332, 2009.

17. Kim JH, Kim GE, Choi YD, Lee JS, Lee JH, Nam JH and Choi C: Immunocytochemical panel for distinguishing between adenocarcinomas and reactive mesothelial cells in effusion cell blocks. Diagn Cytopathol 37: 258-261, 2009.

18. Qureshi-Baig K, Ullmann P, Rodriguez F, Frasquilho S, Nazarov PV, Haan S and Letellier E: What do we learn from spheroid culture systems? Insights from tumorspheres derived from primary colon cancer tissue. PLoS One 11: e0146052, 2016.

19. Yung S and Chan TM: Mesothelial cells. Perit Dial Int 27 (Suppl 2): S110-S115, 2007.

20. Yung S, Li FK and Chan TM: Peritoneal mesothelial cell culture and biology. Perit Dial Int 26: 162-173, 2006.

21. Mutsaers SE, Whitaker D and Papadimitriou JM: Stimulation of mesothelial cell proliferation by exudate macrophages enhances serosal wound healing in a murine model. Am J Pathol 160: 681-692, 2002

22. Zhou Q and Yu X: Isolation and propagation of rat peritoneal mesothelial cells. Methods Mol Biol 1397: 25-34, 2016.

23. Ranieri D, Raffa S, Parente A, Rossi Del Monte S, Ziparo V and Torrisi MR: High adhesion of tumor cells to mesothelial monolayers derived from peritoneal wash of disseminated gastrointestinal cancers. PLoS One 8: e57659, 2013. 
24. Tsukada T, Fushida S, Harada S, Yagi Y, Kinoshita J, Oyama K, Tajima H, Fujita H, Ninomiya I, Fujimura T, et al: The role of human peritoneal mesothelial cells in the fibrosis and progression of gastric cancer. Int J Oncol 41: 476-482, 2012.

25. Cabourne EJ, Roberts G, Goldin R, Ryder T, Mobberly M and Ziprin P: Investigation of tumor-peritoneal interactions in the pathogenesis of peritoneal metastases using a novel ex vivo peritoneal model. J Surg Res 164: e265-e272, 2010.

26. Lv M, Leng JH, Hao YY, Sun Y, Cha N and Wu GP: Expression and significance of MOC-31 and calretinin in pleural fluid of patients with lung cancer. Diagn Cytopathol 43: 527-531, 2015.

27. Hyun TS, Barnes M and Tabatabai ZL: The diagnostic utility of D2-40, calretinin, CK5/6, desmin and MOC-31 in the differentiation of mesothelioma from adenocarcinoma in pleural effusion cytology. Acta Cytol 56: 527-532, 2012.

28. Fetsch PA, Simsir A and Abati A: Comparison of antibodies to HBME-1 and calretinin for the detection of mesothelial cells in effusion cytology. Diagn Cytopathol 25: 158-161, 2001.

29. Zhao L, Guo M, Sneige N and Gong Y: Value of PAX8 and WT1 immunostaining in confirming the ovarian origin of metastatic carcinoma in serous effusion specimens. Am J Clin Pathol 137: 304-309, 2012.

30. Oda T, Ogata S, Kawaguchi S, Minabe S, Dokyu M Takahashi H, Kumazawa F, Shimazaki H, Takano M, Hase K, et al: Immunocytochemical utility of claudin-4 versus those of Ber-EP4 and MOC-31 in effusion cytology. Diagn Cytopathol 44: 499-504, 2016.

31. Kundu UR and Krishnamurthy S: Use of the monoclonal antibody MOC-31 as an immunomarker for detecting metastatic adenocarcinoma in effusion cytology. Cancer Cytopathol 119: 272-278, 2011.

32. Kim NI, Kim GE and Lee JS: Diagnostic usefulness of claudin-3 and claudin- 4 for immunocytochemical differentiation between metastatic adenocarcinoma cells and reactive mesothelial cells in effusion cell blocks. Acta Cytol 60: 232-239, 2016.

33. Ikeda K, Tate G, Suzuki T, Kitamura T and Mitsuya T: IMP3/ L523S, a novel immunocytochemical marker that distinguishes benign and malignant cells: The expression profiles of IMP3/ L523S in effusion cytology. Hum Pathol 41: 745-750, 2010.

34. Hanley KZ, Facik MS, Bourne PA, Yang Q, Spaulding BO, Bonfiglio TA and $\mathrm{Xu} \mathrm{H}$ : Utility of anti-L523S antibody in the diagnosis of benign and malignant serous effusions. Cancer 114 49-56, 2008

35. Jing X, Li QK, Bedrossian U and Michael CW: Morphologic and immunocytochemical performances of effusion cell blocks prepared using 3 different methods. Am J Clin Pathol 139: $177-182,2013$
36. Ebata T, Okuma Y, Nakahara Y, Yomota M, Takagi Y, Hosomi Y, Asami E, Omuro Y, Hishima T, Okamura T, et al: Retrospective analysis of unknown primary cancers with malignant pleural effusion at initial diagnosis. Thorac Cancer 7: 39-43, 2016.

37. Lew M, Pang JC, Jing X, Fields KL and Roh MH: Young investigator challenge: The utility of GATA 3 immunohistochemistry in the evaluation of metastatic breast carcinomas in malignant effusions. Cancer Cytopathol 123: 576-581, 2015.

38. Porcel JM, Palma R, Bielsa S, Esquerda A, Gatius S, MatiasGuiu X and Salud A: TTF-1 and napsin A on cell blocks and supernatants of pleural fluids for labeling malignant effusions. Respirology 20: 831-833, 2015.

39. Moh M, Krings G, Ates D, Aysal A, Kim GE and Rabban JT: SATB2 expression distinguishes ovarian metastases of colorectal and appendiceal origin from primary ovarian Tumors of mucinous or endometrioid type. Am J Surg Pathol 40: 419-432, 2016.

40. Seipel AH, Samaratunga H, Delahunt B, Wiklund P, Clements M and Egevad L: Immunohistochemistry of ductal adenocarcinoma of the prostate and adenocarcinomas of non-prostatic origin: A comparative study. APMIS 124: 263-270, 2016.

41. McKnight R, Cohen C and Siddiqui MT: Utility of paired box gene 8 (PAX8) expression in fluid and fine-needle aspiration cytology: an immunohistochemical study of metastatic ovarian serous carcinoma. Cancer Cytopathol 25: 298-302, 2010.

42. Waters L, Crumley S, Truong L, Mody D and Coffey D: PAX2 and PAX8: Useful markers for metastatic effusions. Acta Cytol 58: 60-66, 2014.

43. Barr ML, Jilaveanu LB, Camp RL, Adeniran AJ, Kluger HM and Shuch B: PAX-8 expression in renal tumours and distant sites: A useful marker of primary and metastatic renal cell carcinoma? J Clin Pathol 68: 12-17, 2015.

44. Chute DJ, Kong CS and Stelow EB: Immunohistochemistry for the detection of renal cell carcinoma in effusion cytology. Diagn Cytopathol 39: 118-123, 2011.

45. Karabork A, Kaygusuz G and Ekinci C: The best immunohistochemical panel for differentiating hepatocellular carcinoma from metastatic adenocarcinoma. Pathol Res Pract 206: 572-577, 2010.

46. Pu RT, Pang Y and Michael CW: Utility of WT-1, p63, MOC31, mesothelin, and cytokeratin (K903 and CK5/6) immunostains in differentiating adenocarcinoma, squamous cell carcinoma, and malignant mesothelioma in effusions. Diagn Cytopathol 36: 20-25, 2008. 